\title{
THE ASSESSMENT OF EVAPOTRANSPIRATION AND SOIL WATER CONTENT IN THE KYSUCA RIVER BASIN (SLOVAKIA) USING RAINFALL-RUNOFF MODEL
}

\author{
Romana Košková ${ }^{1}$, Soňa Němečková ${ }^{1}, Z^{\prime}$ uzana Sitková \\ ${ }^{1}$ The Institute of Hydrodynamics, AS CR, v.v.i. \\ Prague, The Czech republic \\ 2 The National Forest Centre \\ Zvolen, Slovakia \\ koskova@ih.cas.cz,nemeckova@ih.cas.cz,sitkova@nlcsk.org
}

\begin{abstract}
Rainfall-runoff modelling is a commonly used tool for analysis of various aspects in hydrological research. An application of the distributed hydrological model brings the benefits of assessment of the spatial distributed results. However, a huge amount of data is required in this modelling approach. Primarily description of the spatial distribution of soil and vegetation types is an essential task and substantially influences a resulting accuracy. The Kysuca river basin has been chosen for an evaluation of soil water content and evapotranspiration by a distributed hydrological model SWIM (Soil and Water Integrated Model). The basin is located in northwestern Slovakia and covers area of $1016 \mathrm{~km}^{2}$. The primary interest in this analysis was motivated by assessment of forest health conditions in the area and finding possible causes of forest deterioration. Evapotranspiration and soil water content in two selected soil layers in each hydrotop have been evaluated in simulation period 1995 - 1999. The set of the maps each representing an individual day of simulation period has been obtained as a result of the simulation for each variable mentioned above. The results were statistically processed and compared to the available observed data. Further research will be oriented to a comparison with the soil water data having been measured in the selected hydrotops in situ recently (measurement started in 2007).
\end{abstract}

Keywords: hydrologic modelling, soil water content, evapotranspiration, SWIM model.

\section{INTRODUCTION}

Rainfall-runoff modelling is a commonly used tool for analysis of various aspects in hydrological research, recently very often related to the global climate change. This article deals with modelling of evapotranspiration and soil water content in different layers in the mesoscale Kysuca river basin $\left(1016 \mathrm{~km}^{2}\right)$. Soil water conditions are one of the main factors determining conditions of a vegetation cover. The simulations are carrying out as a part of a larger study about the role of different aspects (biotic, abiotic and antropogenic factors) in health state of vegetation cover and its revitalization. It is a typical situation in the Czech and Slovak Republic that mountains are covered by pine-woods, but they are not the original ecosystems. The aim of this article is to describe the soil water conditions and evapotranspiration in the mentioned river basin using the SWIM (Soil and Water Integrated Model). 


\section{HYDROLOGICAL MODEL SWIM}

The model SWIM has been developed in the PIK (Potsdam Institute for Climatic Research, Germany). Two different models SWAT and MATSALU were interconnected into one unified system SWIM (Krysanova et al., 1998). SWIM is a continuous-time distributed simulation watershed model. It was developed to predict the effects of the alternative management decisions on water, sediment, and chemical yields with reasonable accuracy for the ungauged rural basins. It was motivated by water resources management in densely populated agricultural areas (water pollution problem), arid and semi-arid regions (water scarcity), and mountainous and loess regions (erosion problem). The other motivation is an ongoing climate change and land use/land cover change. Development of water resources in the conditions of global change requires an understanding and adequate representation in the models of the basic hydrologic and related processes at mesoscale and large scale, i.e. the in river basins of hundreds, thousands or tens of thousands of square kilometres. The model SWIM was developed in order to provide a comprehensive GIS-based tool for hydrological and water quality modelling in the mesoscale and large river basins, which can be parameterised using regionally available information. The model was intended for the use mainly in Europe and temperate zone, though its application in other regions is possible as well. The model integrates hydrology, vegetation, erosion, and nutrient dynamics at the basin scale. SWIM has a three-level disaggregation scheme 'basin - sub-basins - hydrotopes' and is coupled to the Geographic Information System GRASS (Neteler, Mitasova, 2004). Model test and validation were performed sequentially for hydrology, crop growth, nitrogen and erosion in a number of the mesoscale basins in the German part of the Elbe drainage basin. A comprehensive scheme of spatial disaggregation into sub-basins and hydrotopes combined with reasonable restriction on a sub-basin area allows performing the assessment of water resources and water quality with SWIM in the mesoscale river basins. The hydrological modul of the model is based on water balance in several layers of soil column that includes precipitation, evapotranspiration, percolation, surface runoff, and subsurface runoff (Fig. 1).

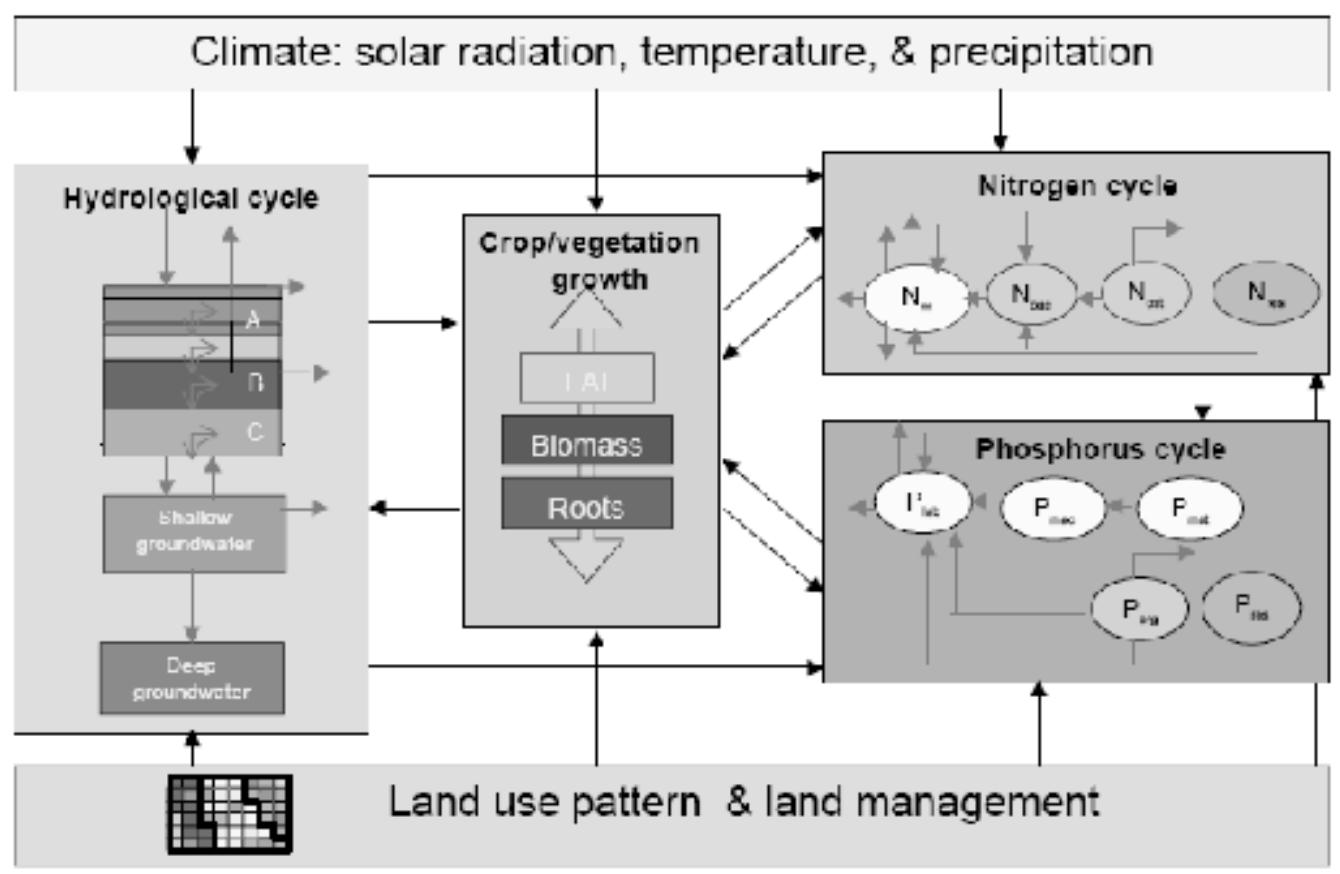

Fig. 1 Flow chart of the SWIM model (Krysanova et al., 1998) 


\subsection{Evapotranspiration evaluation}

An expression of evapotranspiration in the model is based on calculating evaporation from soils and transpiration by plants apart according to Ritchie (1972). The plant transpiration is calculated using value of potential evapotranspiration and LAl (leaf area index). If soil water is limited, plant water transpiration is reduced.

$$
E P=\frac{E O \cdot L A I}{3} \text { if } 0 \leq L A I \leq 3 \quad \text { or } E P=E O \text { if } L A I \geq 3
$$

$E O$....... the potential evapotranspiration $\left[\mathrm{mm}^{-1} \mathrm{~d}^{-1}\right]$,

$E P$........ the plant transpiration $\left[\mathrm{mm} . \mathrm{d}^{-1}\right]$,

$L A I$....... the area of plant leaves relative to a soil surface area.

Potential soil evaporation from a soil surface ESO $\left[\mathrm{mm} \cdot \mathrm{d}^{-1}\right]$ is simulated by an exponential function of the leaf area index according to the equation of Richardson and Ritchie (1973):

$$
E S O=E O \cdot \exp (-0.4 \cdot L A I)
$$

Actual evaporation from a soil surface is calculated in two stages. In the first stage only the energy available at the surface limits the actual soil evaporation, which is equal to the potential soil evaporation in this case. When the accumulated soil evaporation exceeds the first stage threshold (equal to $6 \mathrm{~mm}$ ), the second stage begins after following expression:

$$
E S=3.5 \cdot(\sqrt{T S T}-\sqrt{T S T-1})
$$

ES.... soil evaporation from a soil surface for day $t\left[\mathrm{~mm} . \mathrm{d}^{-1}\right]$, $T S T$... a number of days since stage two evaporation began.

Actual soil water evaporation is estimated on the basis of the top $30 \mathrm{~cm}$ of soil and snow cover, if any. If water content of a snow cover is greater or equal to $E S$, soil evaporation comes from the snow cover. If $E S$ exceeds the water content of the snow cover, water is removed from the upper soil layers if available.

Potential evapotranspiration is estimated using the method of Priestley-Taylor (1972) or Penman-Monteith (1965) according to data availability. The first method requires only solar radiation, air temperature and elevation as inputs. The latter requires solar radiation, air temperature, wind speed and relative humidity as inputs. In this study method of Penman-Monteith has been used.

The SWIM model provides simulation of growing of vegetation during a year using EPIC method according to Williams (1984). The $L A l$ is simulated as a function of heat unit and biomass during a year in this approach. (Krysanova, 1998).

\subsection{Evaluation of soil water content}

The computation of soil water content in the hydrological sub-model in SWIM is based on the following water balance equation:

$$
S W_{(t+1)}=S W_{(t)}+P R E C I P-Q-E T-P E R C-S S F
$$

$S W(t) \ldots . .$. the soil water content in the day $t$,

PRECIP..the precipitation,

$Q$............the surface runoff,

$E T$..........the evapotranspiration,

$P E R C$.....the percolation,

SSF ........the subsurface flow. 
The surface runoff volume is estimated by using a modification of the Soil Conservation Service (SCS) curve number technique (USDA-SCS, 1972; Arnold et al.,1990). The method of evapotranspiration computation is shortly described below. The Subsurface Flow is modeled by the method by Sloan et al. (1983).

The computation of the soil moisture in a soil profile is done with daily steps for the each soil layer in the soil profile. A storage routing technique (Arnold et al., 1990) is used. The method is based on evaluation of daily percolation in the soil layer and the soil water content at the beginning and end of the day. The percolation from the bottom soil layer is treated as recharge to the shallow aquifer. The storage routing technique is based on the equation:

$$
S W_{(t+1)}=S W_{(t)} \cdot \exp \left(\frac{-\Delta t}{T T}\right)
$$

$S W(t+1) ; S W(t) \ldots$ the soil water contents at the beginning and end of the day [mm],

$\Delta t$ the time interval $(24 \mathrm{~h})$,

$T T$ the travel time through layer $[h]$.

The computation follows by determination of the percolation by subtracting $S W_{t}$ from $S W_{t+1}$ in each soil layer:

$$
P E R C=S W\left[1-\exp \left(\frac{-\Delta t}{T T}\right)\right]
$$

PERC .....the percolation rate in each soil layer in $\left[\mathrm{mm}^{-1} \mathrm{~d}^{-1}\right]$,

$T T$..........the travel time is calculated for each soil layer with the linear storage equation:

$H C$.... the hydraulic conductivity in $\left[\mathrm{mm} \cdot \mathrm{h}^{-1}\right]$

$$
T T=\frac{S W-F C}{H C}
$$

$F C$..... the field capacity water content for layer [mm].

The hydraulic conductivity is given by the equation:

$$
H C=S C .\left(\frac{S W}{U L}\right)^{\beta}
$$

SC .... the saturated conductivity for layer in $\left[\mathrm{mm} \cdot \mathrm{h}^{-1}\right]$,

$U L$..... the water content at saturation in $\left[\mathrm{mm} . \mathrm{mm}^{-1}\right]$,

$\beta$....... the shape parameter given by expression:

$$
\beta=\frac{-2.655}{\log _{10}\left(\frac{F C}{U L}\right)}
$$

Water flow through a soil layer may occur until the lower layer is not saturated. If the layer below the layer being considered is saturated, no flow can occur. In this case the percolation is further corrected.

\section{THE KYSUCA RIVER BASIN}

\subsection{Natural conditions}

The Kysuca river basin is located in north-western Slovakia and covers area of $1016 \mathrm{~km}^{2}$. The Kysuca river reaches the Vah river near the town Zilina, its length is $66.3 \mathrm{~km}$. The region is rather mountainous with low population density. A big part of 
the river basin $\left(654 \mathrm{~km}^{2}\right)$ is protected within a natural reservation "The Kysuce". About a half of the basin is covered by forest (45\% - coniferous; $12 \%$ - mixed; $43 \%$ - deciduous). Extent of original fir - beech forest is limited. Dominant ecosystems are monocultures of spruce wood of antropogenic origin, which are less stable than the natural ones.

The geology is determined by the Carpatian flysh formation. It is a specific formation consisting of alternating layers of hard sandstones and soft shales. Because of these conditions there is lack of groundwater storages. Therefore the spring-discharges are low and unsteady. The most extended soil type in the basin is kambisol.

\subsection{Input data}

The distributed model processes a huge amount of data, firstly spatial data describing the river basin, secondly the time series of climatic data and discharge at the outlet of the river basin as well.

Four layers of spatial data for the SWIM model are required: a river network and subbasins, digital elevation model, soil types and land cover. The hydrological model SWIM simulates water conditions in several layers of a soil column that is why detailed soil data are required. There were defined nine soil types (4 agricultural and 5 forest) and eleven vegetation types of land cover in the Kysuca river basin. The soil types were derived according to their physical characteristics from the database of land valuation of Slovakia ("BPEJ") in case of agricultural soils and from the database of forest land resources in case of forest soils. (Fig. 2, Fig. 3 and Fig. 8)

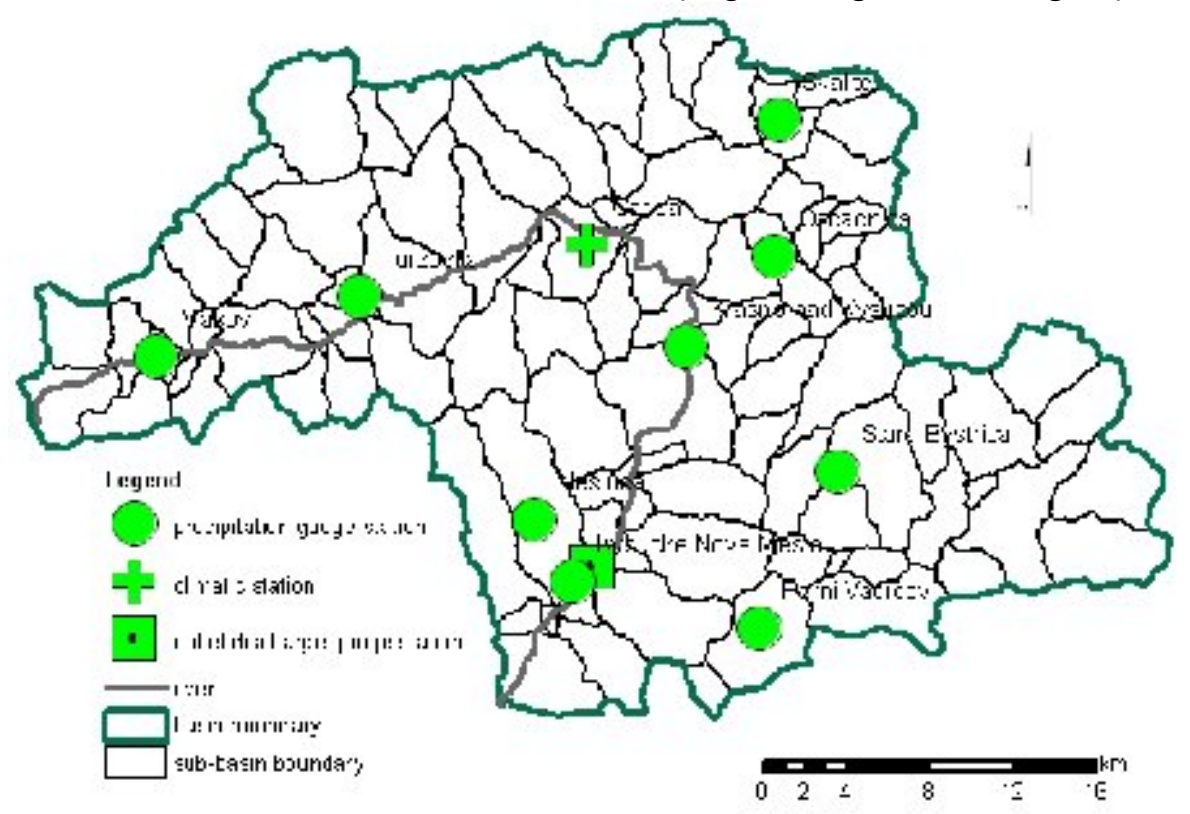

Fig. 2 Sub-basins and gauge stations in the Kysuca river basin 


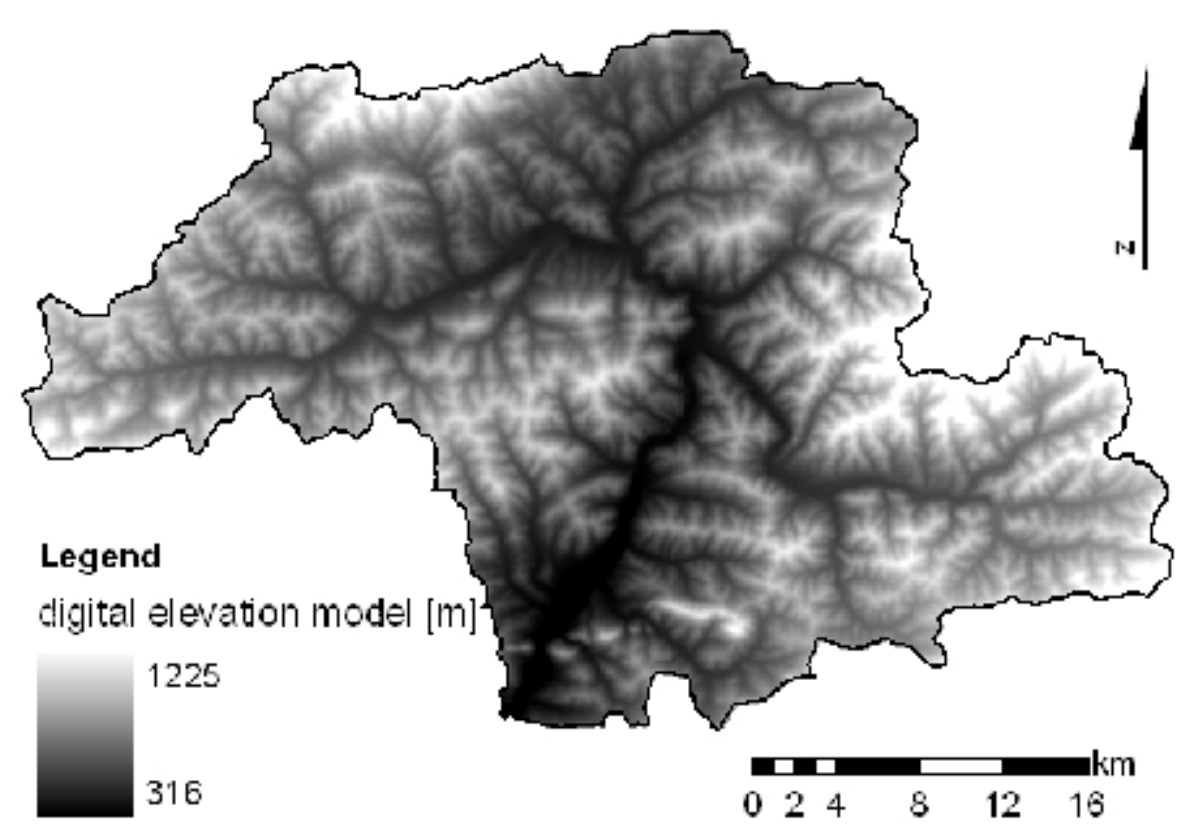

Fig. 3 Digital elevation model of the Kysuca river basin

These geographic data are handled by the by technology of GIS. Finally all the layers were converted into raster forms and consequently into a text format that the SWIM requires as the input. During the GIS process hydrotops are defined by overlaying the four input layers of spatial data.

The climate data necessary to drive the model are precipitation, minimum, maximum and average temperature and solar radiation. The model requires the input of meteorological data mentioned above for each sub-basin in daily step. Nevertheless, there are only 9 precipitation gauge stations providing rainfall data and one climatic station (Čadca) providing beside the rainfall data the temperature, radiation and air humidity measurement, too. Therefore it was necessary to interpolate the variables over sub-basins.

The model was calibrated and validated taking into account discharge at the outlet (Kysucké Nové Mesto) of the Kysuca basin.

\section{SIMULATIONS AND RESULTS}

\subsection{Calibration of the model}

The model was calibrated and validated in the time period from the year 1995 to the year 1999. The simulated and observed discharges at the outlet gauge station were compared (Fig. 4). Nash Sutcliffe efficiency was 0.81 per calibration period and 0.79 per validation period. The water balance in calibration period was $-1 \%$ and for validation period $-2.5 \%$. The output of the model could be described as satisfactory. 


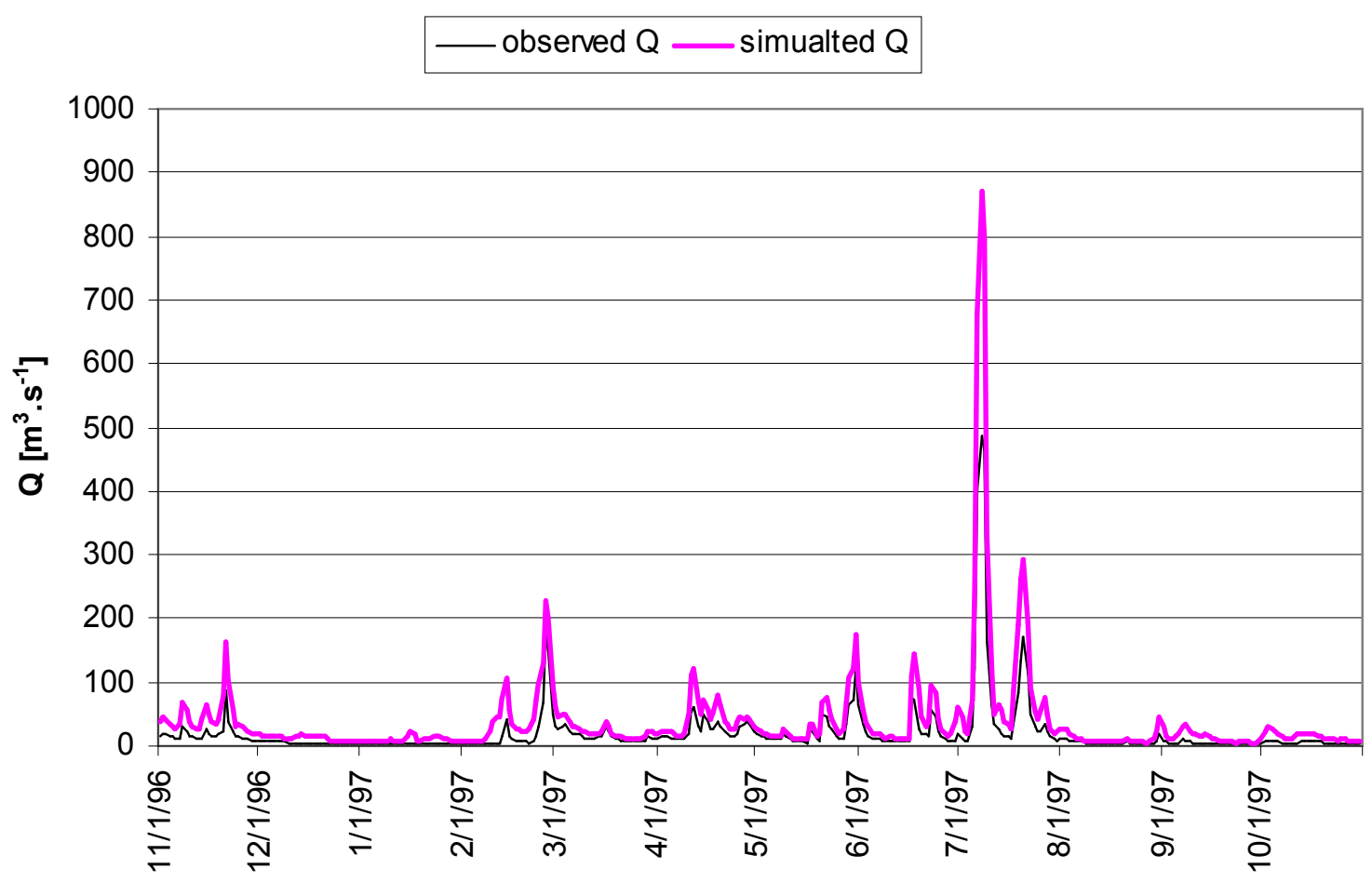

Fig. 4: Comparison of simulated and observed discharge in daily step at the Kysucke

\subsection{Soil water content}

Nove Mesto

Soil water content is not a regularly measured physical quantity. Nevertheless, it is one of the limiting factors of growth and health state of vegetation cover. The simulation should help to explain the relation between them in any given area during a selected time period. The plausibility of soil water simulation results will be evaluated by comparing with observed values of the volumetric water content using statistical methods. The monitoring of the soil moisture was established in May 2007 in eight localities within the Kysuca river basin (see Fig. 5 or Fig. 6). The observations are realized by probes positioned in two depths (15 and $45 \mathrm{~cm}$ ). They measure continuously that means every hour one value is recorded. In addition, selected meteorological elements (temperature, precipitation, radiation and air humidity) are observed close to the localities of the measurement.

The soil water content has been simulated in two out of five soil layers, namely in the second and the third, in accordance with the depths of the observations. The model gives results of soil water content in $\mathrm{mm}$ of a water column in each hydrotop. There are 2255 hydrotops defined in the basin. In order to compare results with the measured data in [\%] they have had to be recalculated. Two maps, each representing an average water content of one layer simulated within the period 1995 - 1999, have been created to visualize the result of the simulation (Fig. 5, Fig. 6). Behavior of soil moisture within one year is an object of further analysis. 


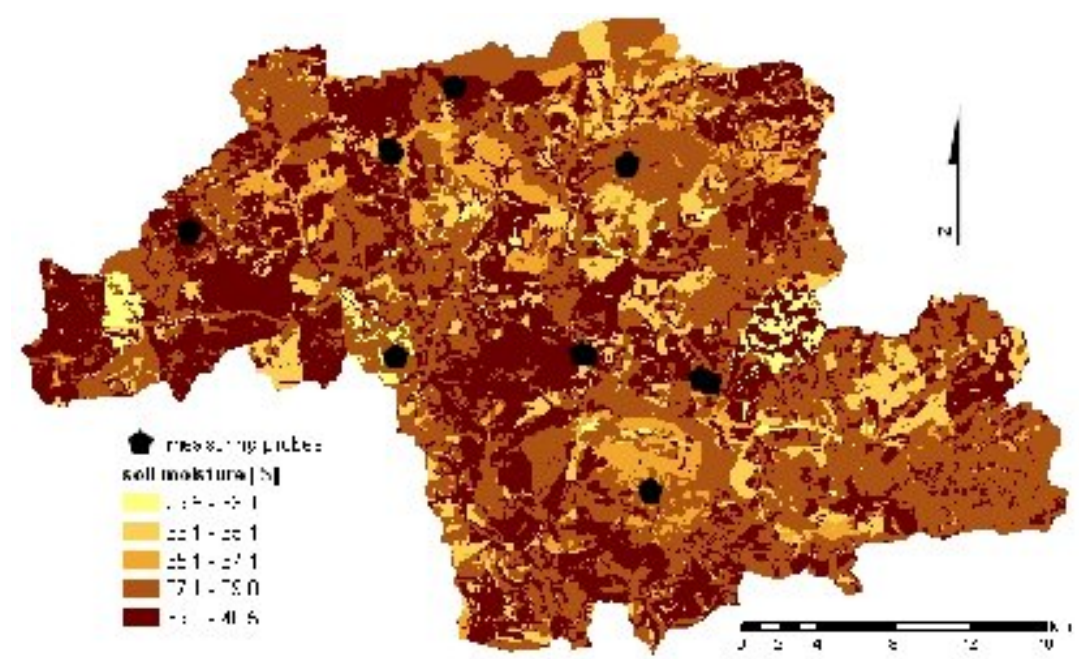

Fig. 5 Map of the simulated average annual soil water content [\%] in $15 \mathrm{~cm}$ depth

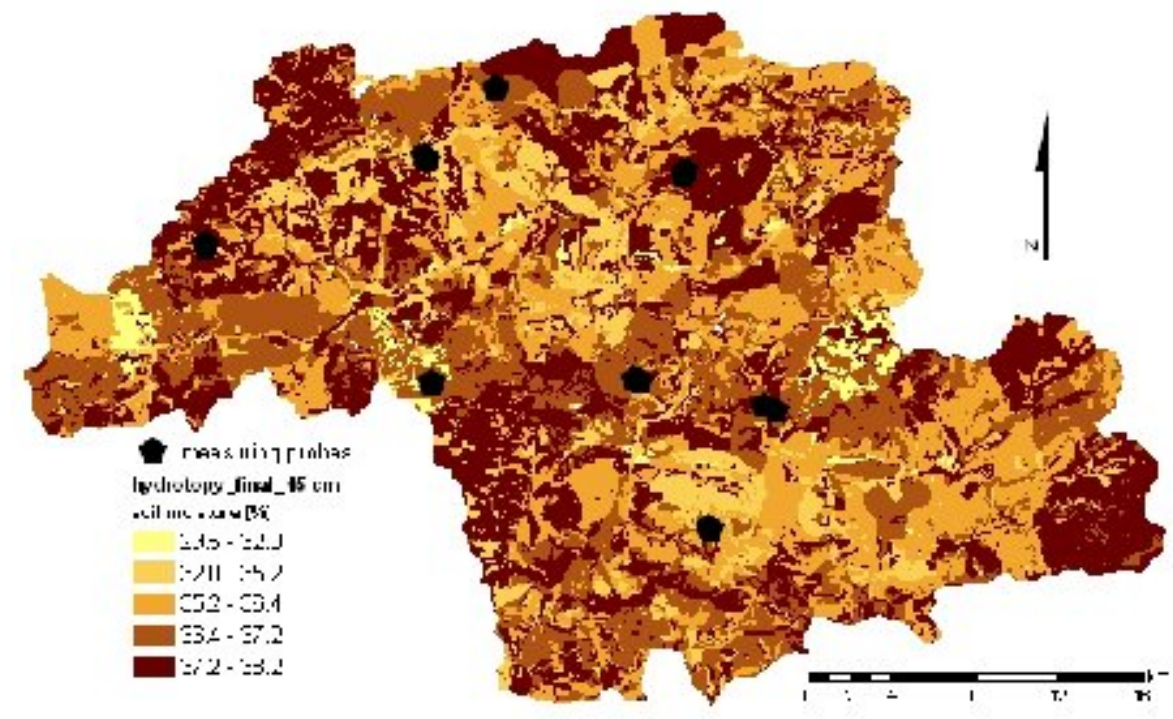

Fig. 6 Map of the simulated average annual soil water content [\%] in $45 \mathrm{~cm}$ depth

Beside the assessment of the behavior of soil moisture during a year the comparison of simulated and observed data was achieved (Fig. 7). It was the first attempt to compare values from one of the measuring localities (Čadečka). The comparison is problematic because of comparing values of different time periods and spatial resolution. The simulated data represent the average soil water content in each soil layer calculated from the period 1995 - 1999 whereas the observed soil moisture data come from point measurements in defined depths during only the year 2007. This fact has probably caused the apparent differences in their time behavior, see Fig. 7. Other potential reason of the discrepancy could consist in different meteorological conditions of the year 2007 from the period 1995 - 1999. Unfortunately, observed climate data have not been processed yet. As soon as these data are available for model, it will be possible to evaluate the simulation accuracy. 


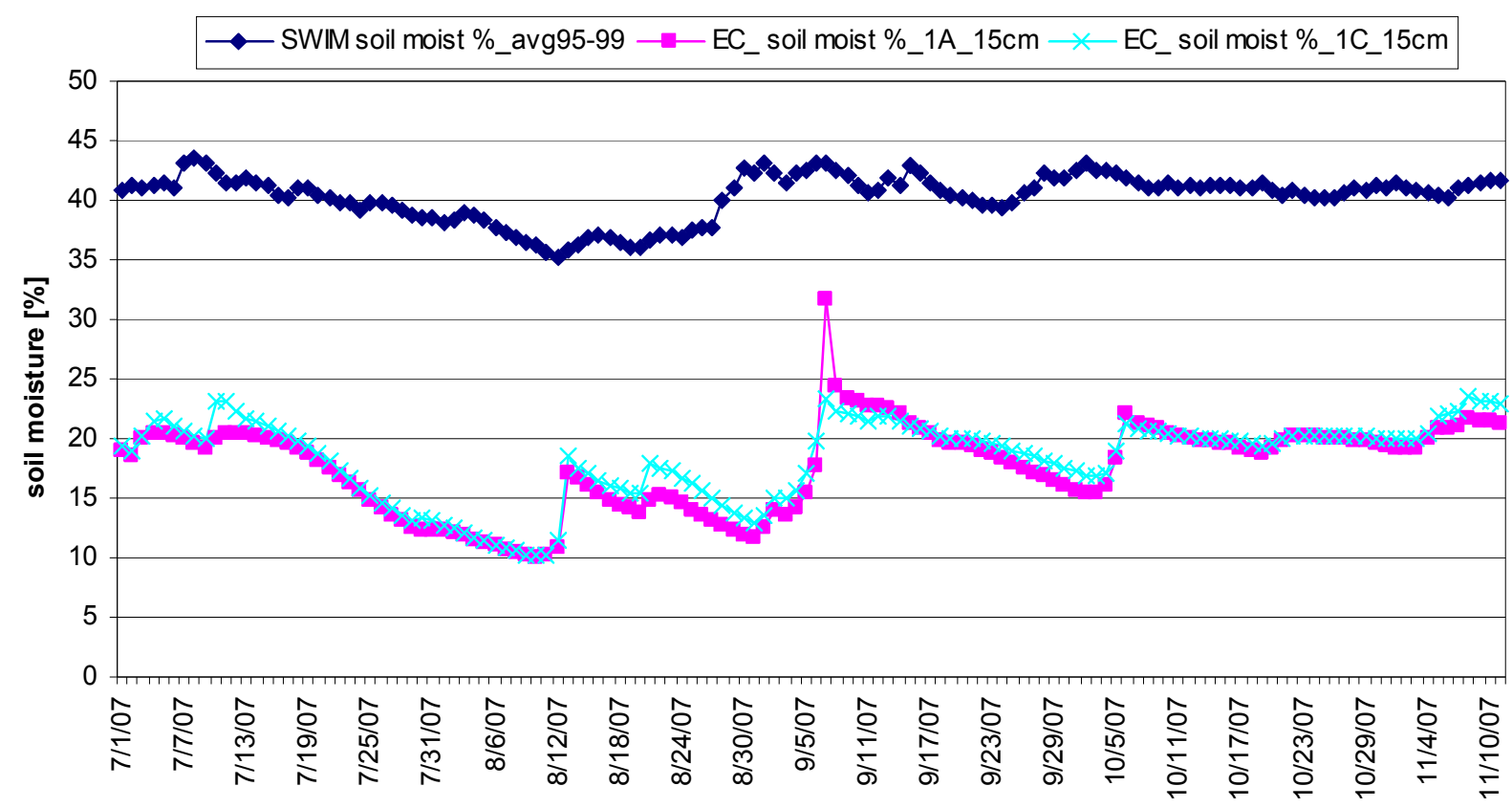

Fig. 7 Comparison of observed values of the average daily volumetric water content in the locality "Čadečka" (1A and $1 \mathrm{C}$ ) and simulated values in the matching hydrotop in the depth of $15 \mathrm{~cm}$

\subsection{Evapotranspiration}

Actual evapotranspiration was simulated in each hydrotop for the period 1995 1999. The average annual values of actual evapotranspiration were obtained in $\mathrm{mm}$ of a water column. Then it was analyzed how the results spatially correspond to data elements entering the model (namely the geographical data about soils and land use), see maps in Fig. 8. The results generally correspond to Tomlain (2003), who states that the annual average evapotranspiration in the region of north-western Slovakia varies from less than $400 \mathrm{~mm}$ up to more than $450 \mathrm{~mm}$ depending on elevation above sea level. Actual evapotranspiration increases with increasing amount of precipitation up to a certain level. After that it decreases due to lack of energy caused by increasing cloud amount and relative air humidity, rising number of days with snow cover and fall of air and soil temperature.

For evaluation of percentage of hydrotops both in each category of land use and each soil group see Fig. 9 and Fig. 10. 

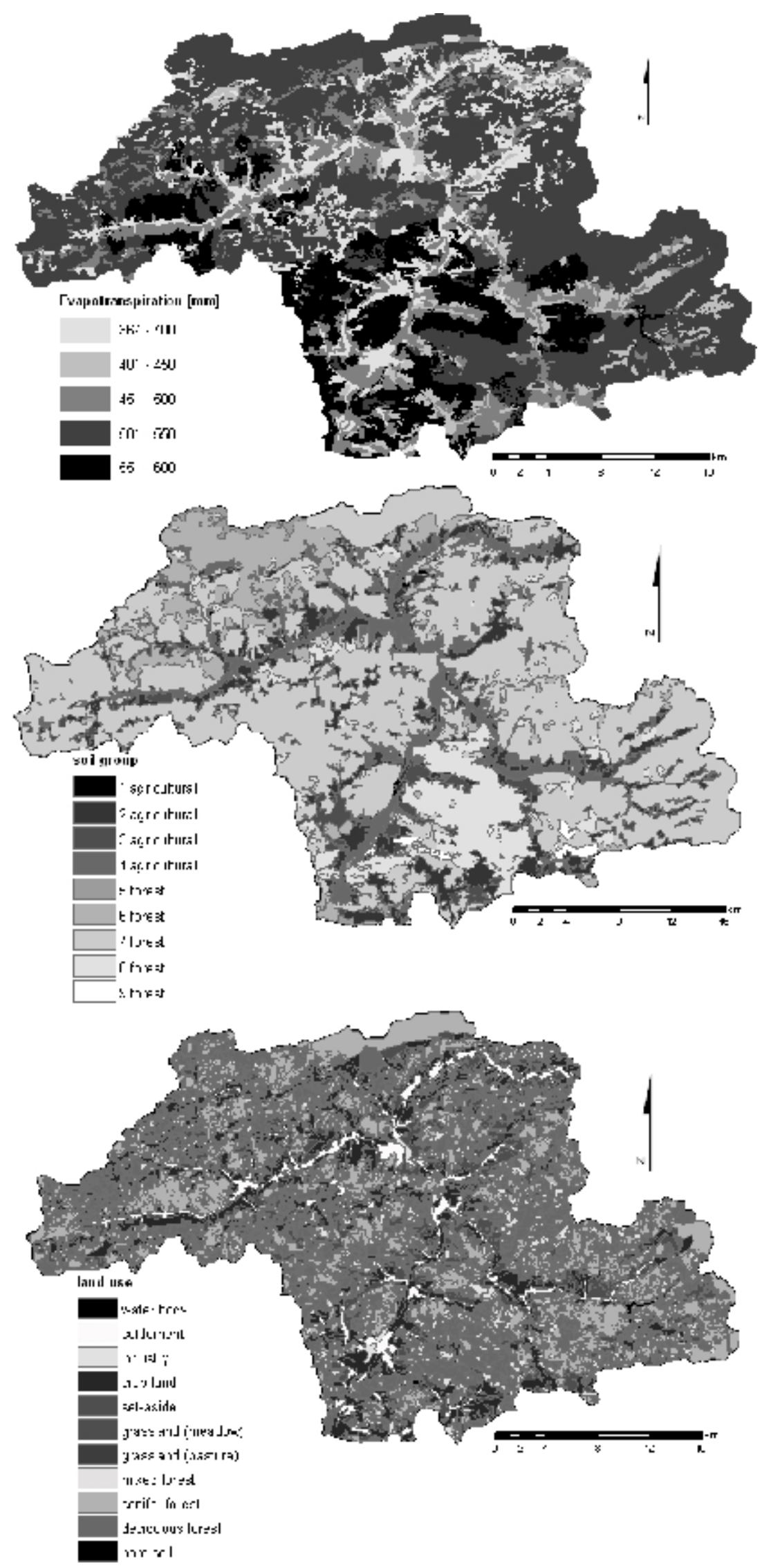

Fig. 8 Comparison of the map of the average annual evapotranspiration with the map of land use and the soil map 


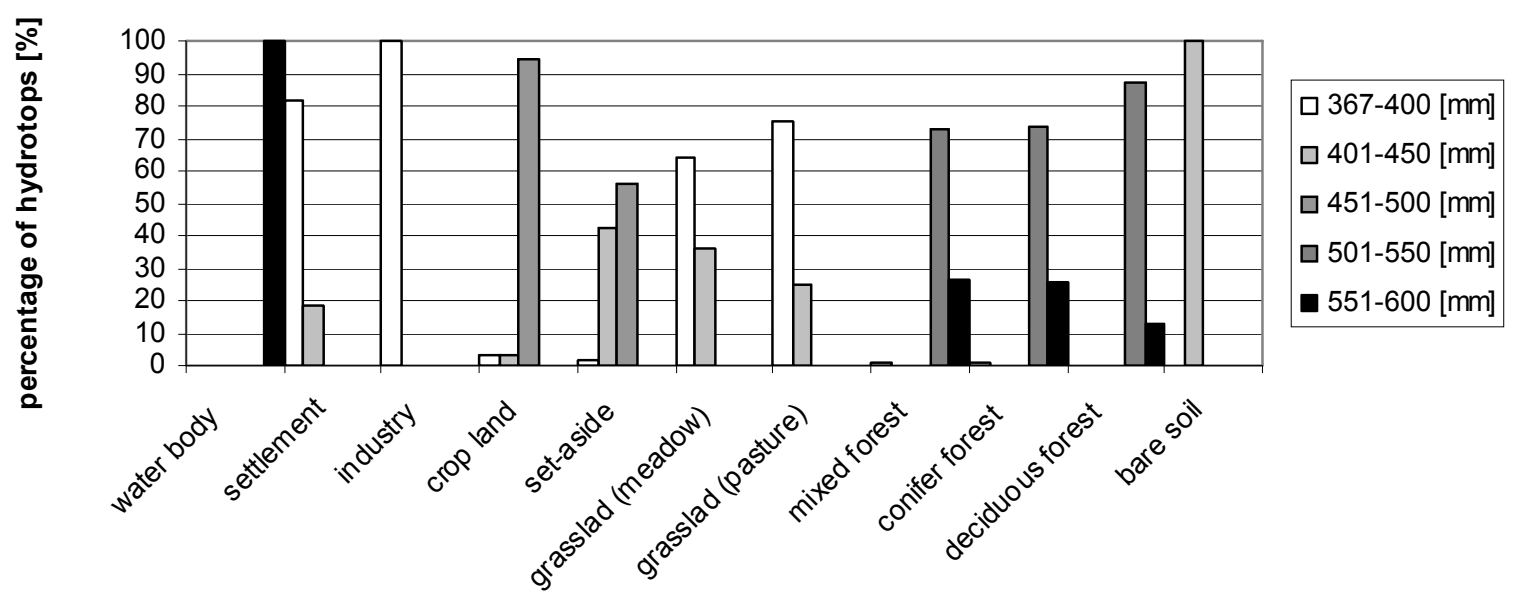

Fig. 9 Percentage of hydrotops in each type of land use in categories of the annual average evapotranspiration

The figures have verified that values of evapotranspiration depend considerably on the type of land use as was expected. The values of evapotranspiration increase according to density of vegetation and the highest ones are reached over forested areas and naturally water bodies.

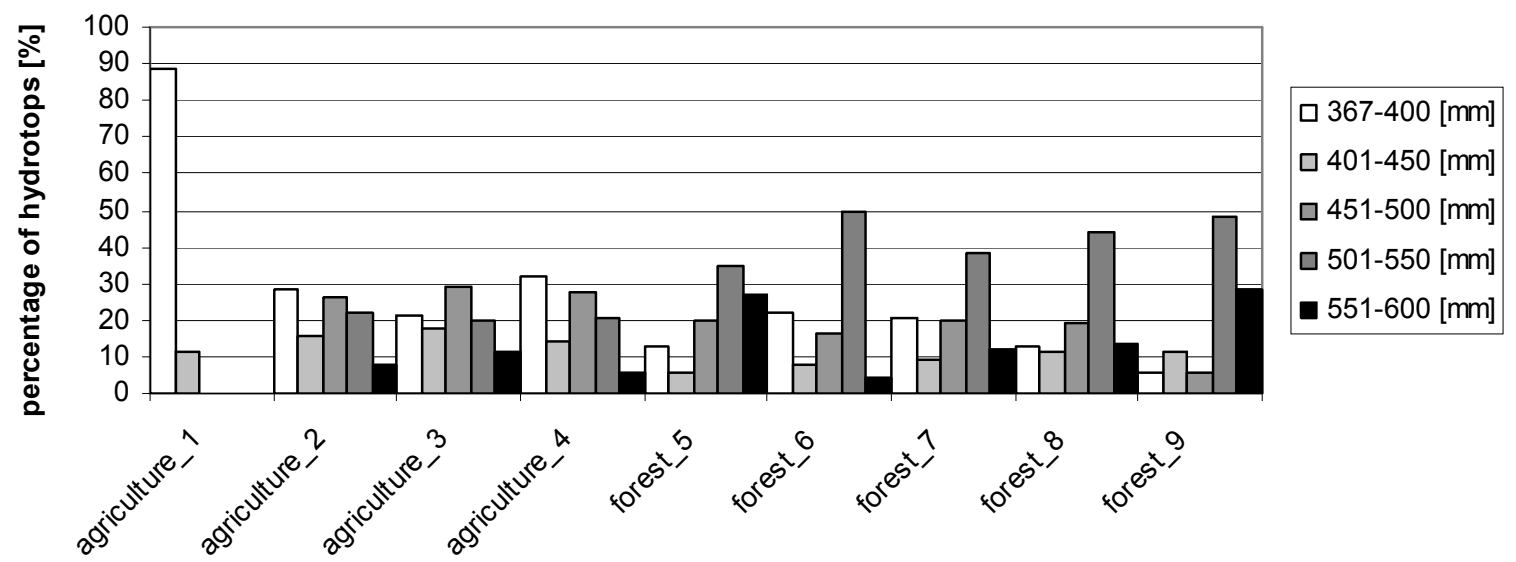

Fig. 10 Percentage of hydrotops of each soil in categories of the annual average evapotranspiration

The effect of the characteristics of individual soil types on the evapotranspiration seems not to be significant. More important is presence or else absence of forest in the hydrotop. The very high percentage of the lowest evapotranspiration category in the type "agriculture_1" is probably caused by the fact that it is very rich in sand (85 $\%)$ and by the very small area it takes over (small number of hydrotops).

\section{CONCLUSION}

It came out that, the SWIM model is a good tool for analysis of hydrological conditions in a river basin. Apart from simulation of discharge also others variables is possible to simulate in various time and spatial step. The outputs can be visualized using further statistical software and GIS. 
The ability of the model SWIM to simulate well rainfall-runoff processes in the Kysuca river basin was proved by the simulation of discharge at the outlet. It could be assumed that other simulated variables, soil water content and evapotranspiration in this study, are satisfactory computed, too. This assumption is supported by establishing of expected relations between evapotranspiration and land cover. Nevertheless, exact accuracy of the model will be tested after getting data of the year 2007 , when the comparison of the same period is carried out.

Obtained results of simulation will then be processed in the study about health state of vegetation cover and its revitalization.

\section{Acknowledgement}

The study was supported by the research grant GA AS CR KJB300600602 and the Institutional Research Plan AVOZ20600510.

\section{References}

Arnold, J. G., Williams, J. R., Nicks, A. D., Sammons, N. B. (1990): SWRRB - A Basin Scale Simulation Model for Soil and Water Resources Management. Texas A\&M University Press, College Station. $255 \mathrm{pp}$.

Krysanova, V., Müller - Wohlfeil, D. I., Becker, A. (1998): Development and test of spatially distributed hydrological/water quality model for mesoscale watersheds. Ecological Modelling, 106, 216 - 289.

Neteler, M., Mitasova, H., (2004): Open Source GIS. A GRASS GIS Approach. Kluwer Academic Publishers/Springer. Boston. Dordrecht.

Monteith, J. L. (1965):Evaporation and environment. Symp. Soc. Exp. Boil. 19. 205-234

Priestley, C. H. B, Taylor, R. J. (1972): On the assessment of surface heat flux and evaporation using large scale parameters. Monthly Weather Review. 100: 81-92.

Richardson, C. W., Ritchie, J. T.(1973): Soil water balance for small watersheds. Trans. ASAE 16(1): 72-77.

Ritchie, J. T. (1972): A model for predicting evaporation from a row crop with incomplete cover. Water Resources Res. 8: 1204-1213.

Sloan, P.G., Morre, I. D. Coltharp, G.B., Eigel, J. D. (1983): Modeling surface and subsurface stormflow on steeply-sloping forested watershed. Water Resources Inst. Report 142. Univ. Kentucky. Lexington.

Tomlain, J. (2003): K rozloženiu evapotranspirácie na území Slovenska za obdobie 1951-2000. In Rožnovský, J., Litschmann, T. (ed): Workshop „Evaporation and evapotranspiration“. Brno. 23. March 2005. ISBN 80-86690-24-5

U. S. Department of Agriculture, Soil Conservation Service (1972): National Engineering Handbook, Hydrology Section 4.

Williams, J. R., Renard, K. G., Dyke, P. T. (1984): EPIC - a new model for assessing erosion's effect on soil productivity. Journal of Soil and Water Conservation 38(5): 381-383. 